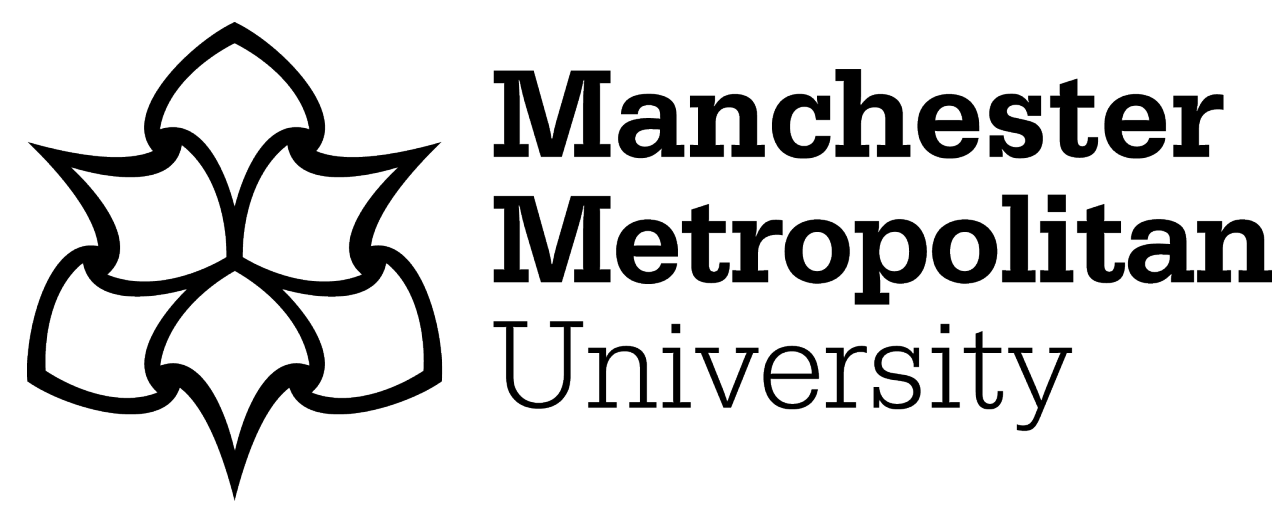

Bonetti, Francesca, Pantano, Eleanora, Warnaby, Gary ORCID logoORCID: https://orcid.org/0000-0002-6696-6671 and Quinn, Lee (2020) Augmented Realities: Fusing Consumers' Experiences and Interactions with Immersive Technologies in Physical Retail Settings. International Journal of Technology Management, 13 (3/4). ISSN 0267-5730

Downloaded from: https://e-space.mmu.ac.uk/622587/

Version: Accepted Version

Publisher: Inderscience

DOI: https://doi.org/10.1504/IJTMKT.2019.104592

Please cite the published version 


\title{
Augmenting Reality: Fusing Consumers' Experiences and Interactions with Immersive Technologies in Physical Retail Settings
}

\begin{abstract}
Drawing upon previous research into immersive environments and technologyenhanced stores, this exploratory study elucidates the concept of the 'augmented store' - a physical store modified to accommodate augmented reality (AR) technology. In doing so, it extends previous research conducted in experimental laboratory settings to an empirical real-world scenario. Qualitative data gathered from interviews with, and observation of, consumers using AR technology in-store are analysed to provide naturalistic understandings of interactions with, and perceptions of, a physical store enhanced with AR technology. Findings suggest that consumers appreciate the ability to experience an enhanced, more immersive store environment arising from the AR experience. They perceive interaction with the augmented store to be 'realistic' and articulated hedonic motivations as drivers for interaction in this shopping environment. The augmented store appears to stimulate brand engagement, increasing consumers' desire to shop at the retailer, providing managerial opportunities to reinforce brand positioning.
\end{abstract}

Keywords: retailing; human-computer interaction; augmented store; augmented reality; consumer behaviour

\section{$1 \quad$ Introduction}

Atmospherics (i.e. design, ambient and social factors, such as store layout and displays, music, lightning and colours, and staff and shoppers) are acknowledged as 
critical elements of the retail store environment, which help convey a satisfactory shopping experience and, ultimately, influence consumer behaviour (Kotler, 1973; Puccinelli et al., 2009). Such factors are arguably even more relevant in fashion retailing, given the multi-sensory experience of both store environment and the products themselves (Foster and McLelland, 2014; Hwangbo et al., 2017). In an emerging technology-driven and increasingly competitive context, fashion and apparel retailers are increasingly implementing digital technologies in-store, to enhance the shopping experience, improve customer service quality, and achieve competitive advantage (Bell et al., 2017; Bonetti and Perry 2017; Bonetti et al., 2017, 2018; Hwangbo et al., 2017; Inman and Nikolova, 2017; Kannan and Li, 2017; Pantano 2015; Poncin et al., 2017; Roy et al., 2017; Sorescu et al., 2011; Willems et al., 2017). This also provides learning opportunities for retailers, who can analyse technology-generated data on consumer behaviour to adjust company strategy and objectives more efficiently (Ailawadi and Farris, 2017; Hwangbo et al., 2017; Kannan and Li, 2017; Willems et al., 2017), thereby contributing to the continual shaping of retail business models (Bell et al., 2017; Bozer and Aldarondo, 2018; Verhoef et al., 2015) and consumer behaviours (Ailawadi and Farris, 2017; Hwangbo et al., 2017). As part of retail business model innovation - consisting of reconfiguring individual retail activities to create value and build sustainable competitive advantage in a marketplace (Chesbrough, 2010; McGrath, 2010) - some retailers might decide to use innovative customer interfaces to enhance the customer experience, as part of a 'system-wide change' (Sorescu et al., 2011) to retail business models. Such innovative customer interfaces - e.g. digital signage screens and interactive touch points, mobile apps, payment processes, beacon technology, magic mirrors, augmented reality (AR), virtual reality (VR), contactless technologies, etc. (see 
Bonetti and Perry, 2017; McCormick et al., 2014; Pantano et al., 2017) - can be referred to as 'consumer-facing' in-store technology (Bonetti and Perry, 2017).

Immersive technologies such as AR and VR are currently of great interest to fashion, apparel and beauty retailers and software developers (Bonetti et al., 2017; Javornik, 2016). In particular, they enrich content delivery (including product information, stock availability, style advice etc.) through new interactive modalities between consumers and product, combining real-world attributes (i.e. the possibility to touch the product) with virtual/augmented opportunities (i.e. the possibility to see the product functioning in a virtual reconstructed and explorable world). Indeed, AR enables consumers to interact smoothly with virtual items, blending the virtual and real worlds (Huang and Liao, 2015) through a virtual layer that can add images, textual information, videos or other elements to the user's viewing of the physical environment in real time (Carmigniani et al., 2011). AR is designed to combine 'real and computer-generated digital information into the user's view of the physical world in such a way they appear as one environment' (Olsson et al., 2013, p.288). Through its mix of virtual and "effective" reality, AR overcomes some of the limitations of traditional VR systems that incorporate a complete immersion of real humans in a virtual world (Carmigniani et al., 2011; Fuchs and Schreirer, 2011). Whilst VR blocks out real-world sensory experiences through a wearable device (typically a headset) and immerses the user in virtual and entertaining 3D worlds (Bonetti et al., 2017), AR allows users to experience enhanced and more realistic experiences within the physical place itself (Papagiannidis et al., 2017; Rauschnabel, 2018), resulting in an enhanced - or augmented - physical world (Carmigniani et al., 2011; Pantano et al., 2017). 
Although previous studies have investigated immersive environments and technology-enhanced stores, they were conducted in experimental laboratory settings rather than in real-world locations (Huang and Liao, 2015; Kjeldskov and Graham, 2003; Papagiannidis et al., 2017). Consequently, analysing the integration of immersive AR tools within the traditional point-of-sale store environment (i.e. existing stores that are modified to accommodate AR technology) is a novel aspect in developing our understanding further. Our study aims to address the effect of AR in a physical store environment with actual consumers, in order to explore users' interactions with - and perceptions of - this environment enhanced with AR technologies, and which consequently, could be considered a new retail form; namely, the 'augmented store'. We define the augmented store as a real physical retail store enhanced, from the customer's perspective, through the integration of innovative and immersive AR technologies as a key element of the store design. This leads to the development of our research questions:

$R Q 1$. To what extent can traditional physical stores integrate immersive technologies such as AR, to develop new store formats/concepts?

$R Q 2$. What is the consumer's response towards the resulting 'augmented store'?

$R Q 3$. How do consumers interact with the new augmented store?

In addressing these questions, our research contributes to existing literature on:

(1) augmented and immersive places within the context of a specific place type namely the 'real-world', physical retail store - outlining the notion of the 'augmented store' and its key characteristics, and providing an illustrative framework for conceptualising this form of store; 
(2) on human-computer interaction (HCI) by focusing on consumer interaction with technology (consumer-computer interaction or CCI) in such real-world retail settings of an actual store; and,

(3) also investigates the perceptions of current actual consumers of the retailer in question, in terms of their interactions with and reactions to the new and enhanced store space.

\section{Theoretical background}

The literature review below analyses the latest consumer-facing in-store technologies adopted by retailers; the usage of augmented reality in retailing; drivers and barriers for retailers' adoption of AR; and consumers' acceptance and adoption of AR. Subsequently, the concept of 'augmented places' is introduced and explicated. The review concludes with a discussion of human-computer interaction in retail settings enriched with immersive technologies.

\subsection{Consumer-facing technologies in retailing}

Advances in technologies provide new systems that can be introduced into stores to enhance shopping experience. As Sorescu et al. (2011) pointed out, a retailer's ultimate goal is to confer a rewarding customer experience, where innovative technologies are at times used to engage with the end customer. These include digital signage and smart mirrors (Dennis et al., 2014; Roggeveen et al., 2016), robotic shopping assistants (Bertacchini et al., 2017), contactless technologies and other devices enabling fast payment (Pham and Ho, 2015; Schierz et al., 2010).

Digital signage, and its evolution as smart mirrors, consists of stationary interactive touchscreen displays allowing consumers to perform several tasks (Rauschnabel, 
2018). In the case of the smart or virtual mirror, it allows shoppers to virtually try on clothing or make-up. For example, in 2018, Guerlain's magic mirror at Selfridges' London department store allowed customers to customize the lipstick My Rouge (in terms of shades, case and style), and with a camera integrated into the display, to virtually try it on through realistic visualisation combined with the user's skin and lip colour detection. This allowed consumers to buy a customised product and also share the picture online (via social media, email, etc.). Similarly, in-store large smart mirrors allow clothes to be shown in colours and sizes that are not available in-store, to offer virtual fitting and recommendation services (Hwangbo et al., 2017). To this end, the Japanese retailer Uniqlo deployed augmented trial rooms in selected stores in 2013 to enhance customer experience by enabling consumers to choose garments to try on and then overlaying different colours of the clothing on a magic mirror to help them make the best choice without needing to physically change their clothing.

Similarly, automated robots, traditionally used to support back-end operations such as fulfilment and logistics, are now introduced into stores to provide new interaction modalities for consumers (Bertacchini et al., 2017). Research has demonstrated the importance of such 'shopping assistants', since they are able to recognize customers, learn from their behaviour, and adapt their response accordingly through more customised services (Bertacchini et al., 2017).

However, of the developing forms of consumer-facing in-store technologies adopted by retailers, this study focuses on augmented reality. This form of immersive technology has drawn particular attention from both academics and industry practitioners, as the growing diffusion of personal mobile technology has contributed to AR applications becoming more popular, while various retailers are engaging with 
this technology (Bonetti et al., 2017; Javornik, 2016; Pantano et al., 2017). The next section explores AR's key characteristics, forms of AR applications, retailers' drivers for and barriers against AR adoption, and consumers' adoption and usage of this technology.

\subsection{Emergence of augmented reality in retailing}

A major theme in the existing literature relates to the way(s) in which users adopt, interact with, and experience technology devices and systems (see Dix, 2009; Kjeldskov and Graham, 2003; Rogers, 2004). Advances in digital technologies provide new opportunities for retailers to enhance their physical store environments. In particular, immersive technologies have drawn the attention of scholars and practitioners (Bonetti et al., 2017; Javornik, 2016; Pantano et al., 2017), and especially AR, which is based on a camera able to capture real-world data and combine information from real and virtual sources into one perception (Ailawadi and Farris, 2017; Hwangbo et al., 2017; Oleksy and Wnuk, 2016). Consequently, product simulation, sound, GPS data and media richness contribute to experiential value, with AR enabling consumers to interact with virtual products (McCormick et al., 2014).

Early research into AR used in a physical retail environment through interactive displays predicted users interacting with this steerable technology and triggering information on the product, promotions and locations (Sukaviriya et al., 2003), thereby highlighting both its functional and hedonic aspects. Subsequently, AR applications have become more popular due to widely distributed personal mobile technology, such as smartphones and tablets, allowing users to shop using AR apps (Rauschnabel, 2018), thereby enhancing satisfaction and experience (Dacko, 2016; Javornik, 2016). 
Early AR retail applications included virtual try-on using personalised or nonpersonalised virtual models, to show how apparel products (and combinations) would look, and interactive displays providing information on promotion, products and locations (Bonetti et al., 2017; Hwangbo et al., 2017). Subsequently, AR technology has evolved and a substantial growth of mobile AR took place, via the widespread adoption of smartphones and tablets (Javornik, 2016; Rauschnabel, 2018). Mobile AR apps constitute a form of consumer-led interactions, personalisation, and customisation, such as IKEA's AR app which is able to measure a real-life room through the camera's objective and render a very accurate piece of furniture (Tabusca, 2014).

Thus, AR has the potential to improve consumers' visualisation of products, increase engagement and enhance perceptions of the shopping experience, thereby hopefully affecting retailer and brand perception positively. This, in turn, can influence consumer behaviour (Huang and Liao, 2015; Hwangbo et al., 2017; Kannan and Li, 2017; McCormick et al., 2014; Poncin et al., 2017; Willems et al., 2017). Furthermore, consumers' perceived control and autonomy contribute to enhance the retail experience in technology-mediated retailing (Poncin et al., 2017). In fact, letting consumers maintain a degree of control, whilst maintaining a degree of challenge designed to increase the perception of user competence, leads to consumers' perceived enjoyment and to an increase in shopping effectiveness, control and convenience (Roy et al., 2017). Overall, this impacts positively on the customer's perception of the retailer, and on their behavioural intentions (Roy et al., 2017). At the same time, however, information accessibility and consumers' degree of 
perceived control over the collection and use of personal information by companies may lead to privacy concerns (Inman and Nikolova, 2017; Kannan and Li, 2017).

\subsubsection{AR adoption by retailers and consumers}

Other important aspects relating to AR adoption in retailing include retailers' drivers and motivations for the adoption of the technology, as well as barriers. The former might include enhancing the customer experience, both in physical and online stores, by offering additional product information and/or allowing faster product try-on and simulation of product combinations, thereby improving operational efficiency and focusing on the utilitarian benefits of the technologies (Bonetti et al., 2018; Hwangbo et al., 2017; Inman and Nikolova, 2017; Javornik, 2016). Other motives include the facilitation of online-offline shopping connection, and accurate product inventory management for operational cost management and cost savings (Kannan and Li, 2017; Willems et al., 2017). AR adoption might also provide benefits relating to brand image and identity, associated for instance with being perceived as an innovative player by consumers and competitors (Bonetti et al., 2017).

Potential barriers to $\mathrm{AR}$ adoption might relate to the fact that adequate return on investment (ROI) is not guaranteed, and it is not always possible to measure which factor(s) contribute to enhancing consumer experience and influencing their behaviour, thereby isolating the contribution of AR technologies (especially when adopted together with other point-of-sale technologies and retail design factors) to the customer experience. Other barriers to $\mathrm{AR}$ adoption can include the high costs associated with technology adoption and implementation (Bonetti et al., 2018; Willems et al., 2017), as well as compatibility with existing retailers' systems, and technology maintenance, update and repair (Jetter, 2018), and low levels of 
technology expertise among - and commitment of - the retailer's employees, where acceptance from the retailer's staff is necessary to then promote the technology to the customer (Bonetti et al., 2017; Inman and Nikolova, 2017; Piotrowicz and Cuthbertson, 2014; Roy et al., 2018; Zagel, 2016).

Finally, consumers' degree of familiarity with, acceptance, and adoption of innovative technologies such as AR applications - both in-store retail applications, and in the form of customer-owned technologies such as AR Smart Glasses and ARapps on mobile devices (Dacko, 2016; Javornik, 2016; Pantano and Priporas, 2016) and the resulting behavioural reaction(s), where cultural barriers, low perceived benefit and familiarity might lead to consumers' resistance to innovation (Ram \& Sheth, 1989), play an important role in retailers' decisions to adopt the technology (Inman and Nikolova, 2017; Jetter, 2018; Kannan and Li, 2017; Roy et al., 2017; Roy et al., 2018). Here, Inman and Nikolova (2017) stressed the role of shoppers' attitudes, trust, and degree of technology intrusiveness on their personal privacy as mediating their behavioural reactions and intentions towards the technology. Users' perceived threat to their (and other peoples') privacy by AR technologies (in the form of cameras and other sensors used to integrate virtual with real-word information that could collect amounts of user information outside their control) could in fact affect the perceived trustworthiness of the technology and affect decisions towards technology adoption and usage (Rauschnabel et al., 2018).

Important managerial implications can be derived from this, as technological progress does not necessarily correspond to consumers' acceptance and usage of new forms of technology (Bonetti et al., 2017, 2018; Poncin et al., 2017; Roy et al., 2017; Willems et al., 2017), and Davis' (1989) technology acceptance model (TAM) has traditionally 
been considered a key tool to measure the discrepancy between the technological innovations which both consumers and organisations are expected to use, and those that they will accept and use (Bonetti et al., 2017).

\subsection{Augmented places}

The development of the technologies outlined above potentially contributes to the creation of immersive (augmented) places/environments, increasing users' levels of engagement, enjoyment and satisfaction, thereby leading to enhancement of the user experience (Papagiannidis et al., 2017). Augmented places consist of real-world, physical places, enhanced by AR technologies to amplify users' overall current perception of reality, their experience, and the possibilities offered by the real world (Carmigniani et al., 2011; Hwangbo et al., 2017; Oleksy and Wnuk, 2016; Pantano et al., 2017). This helps confer a richer, more immersive and integrated environment and an enhanced experience, tied to the current real and augmented context surrounding the user (Carmigniani et al., 2011; Chang et al., 2015; Oleksy \& Wnuk, 2016; Pantano \& Servidio, 2012; Pantano et al., 2017), leading to a deeper level of engagement, enjoyment and satisfaction (Dacko, 2016; Papagiannidis et al., 2017).

Existing literature on immersive places arising from the use of AR technology mainly focuses on the entertainment and educational sectors, and museums/other places of historic cultural heritage (Chang et al., 2015). Cultural and tourism applications include immersive installations in museums, such as apps for sightseeing and wayfaring, portable smart guides, and systems using AR visualisation to virtually reconstruct ancient ruins and inform users about the site's history (Carmigniani et al., 2011; Chang et al., 2014), which may increase visitors' understanding of the cultural heritage and enhance their immersion in the local context (Chang et al., 2015). In the 
educational field, mobile AR context-aware technologies enable participants to interact with digital information embedded within immersive learning environments (Dunleavy \& Dede, 2013), enhancing education and facilitating the learning process (Martínez et al., 2014).

AR technologies potentially enable a deeper place-based participation by allowing users to experience virtually, yet naturally, an enhanced version of the physical space in real-time via realistic interfaces. This increases feelings of immersion and engagement (Oleksy and Wnuk, 2016; Pantano et al., 2017), and can result in improved perceptions of the experience and the real environment, by offering new possibilities to see objects not physically available in the real-world context, thereby enriching content and information at the users' disposal (Oleksy and Wnuk, 2016; Papagiannidis et al., 2017). Oleksy and Wnuk (2016) introduced the concept of 'augmented places' as physical places enhanced with AR, to recreate and enhance the experience of the place in question, through overlapping virtual reconstructions of past heritage and actual place, supporting users' understanding of its historical value, and resulting in users' higher emotional attitude towards the place and greater understanding of meaning of multicultural places.

These elements of immersive environments and augmented places could potentially be extended to the retail context, due to the increasing efforts by retailers to enhance customer experience through the adoption of immersive technologies. However, studies exploring such 'immersive' retail stores are limited and mainly relate to online places and virtual environments (Altarteer et al., 2017; Childers et al., 2001; Pantano \& Laria, 2012; Pantano \& Servidio, 2012; Willems et al., 2017). 
In contrast to the concept of retail spaces (such as shopping centres) that could be regarded as 'non-places', since they do not empower people's identities and relationships but remain neutral and anonymous (Augé, 1992), the new augmented store emerges as a new place where an individual is immersed in the product/brand identity in a simultaneously virtual and real world that enhances the interaction between individual and context to provide a more rewarding experience (Chang et al., 2015; Papagiannidis et al., 2017). This interaction and overlapping of realities augments and extends the users' perception of the (shopping) place (Oleksy \& Wnuk, 2016; Pantano et al., 2017). To this end, the following section explores in-store human-computer interaction.

\subsection{In-store human-computer interaction (HCI)}

In order to facilitate technology acceptance, software developers need to provide interactional modality that is as realistic and natural as possible (Carmigniani et al., 2011). The quality of this interaction (i.e. HCI) can be evaluated through laboratory experiments and field studies, where the users would normally interact with the technology in question (Dix, 2009; Kjeldskov and Graham, 2003; Papagiannidis et al., 2017), allowing researchers to reflect on a given interface to inform system building and design decisions, to optimise the user experience when interacting with digital systems (Willems et al., 2017). Consumers' acceptance of, and interaction with, technological innovations in retail settings has received greater attention due to the growing adoption of technologies at the point of sale to enhance customer experience and increase competitiveness (Bonetti and Perry, 2017; Hwangbo et al., 2017; Poncin et al., 2017; Willems et al., 2017). 
Several studies have explored consumers' acceptance and interaction with technological innovations in technology-enhanced retail settings. In particular, at a point in time in which retailing is increasingly adopting innovative technologies to enhance the shopping experience, research on human-computer interaction in retail settings enriched with enhanced and immersive AR and VR technologies has started to grow. For instance, Pantano et al (2017) investigated the effect of customer interaction with $\mathrm{AR}$ technologies on experience and buying behaviour within the online retail environment when virtually trying on glasses to simulate fit and appearance. Results of the study, conducted in a controlled laboratory environment, showed that aesthetic quality and interactivity emerged as antecedents of perceived ease of use, and response time and quality of information were antecedents of perceived usefulness. These, in turn, influence consumers' positive attitude, combined with perceived enjoyment when interacting with the technology in the enhanced e-commerce website, thereby improving the online buying decision process. Olsson et al. (2013) assessed potential end users' expectations and requirements of future mobile AR services characteristics and user experience in a shopping centre context to understand, and more effectively influence, the user experience of future applications. Participants expected the technology to be proactive and context-aware in suggesting products and activities based on the user's specific location, as well as providing relevant and personalised content. Furthermore, users envisioned experiences related to mobile AR interaction to be based on mobile device screens, and interaction to be intuitive, natural and easy to learn through realistic interfaces, and flexible and controlled by the user, whilst giving straightforward and instant access to information. Dacko's (2016) examination of mobile AR apps and the extent to which they contribute to smart retail settings also 
found that user satisfaction is relatively high, with the use of the technology providing experiential shopping benefits, including more efficient or better value shopping, more entertaining shopping and more visually appealing shopping.

Table 1 provides a typology of the main studies on human-computer interaction in retail settings enriched with VR and/or AR.

\begin{tabular}{|c|c|c|c|c|}
\hline Author(s) & Methodology & $\begin{array}{l}\text { Examined } \\
\text { technology } \\
\text { application(s) }\end{array}$ & $\begin{array}{l}\text { Channel \& Store } \\
\text { type/ tested in } \\
\text { laboratory }\end{array}$ & Product type \\
\hline $\begin{array}{l}\text { Carmigniani et al. } \\
\text { (2011) }\end{array}$ & $\begin{array}{l}\text { Literature } \\
\text { review }\end{array}$ & AR & Physical store & Apparel \\
\hline $\begin{array}{l}\text { Laria \& Pantano } \\
\text { (2011) }\end{array}$ & Quantitative & VR & $\begin{array}{l}\text { Online store; } \\
\text { Tested in } \\
\text { laboratory }\end{array}$ & Apparel \\
\hline $\begin{array}{l}\text { Pantano \& } \\
\text { Servidio (2012) }\end{array}$ & Quantitative & VR & $\begin{array}{l}\text { Online store; } \\
\text { Tested in } \\
\text { laboratory }\end{array}$ & Apparel \\
\hline $\begin{array}{l}\text { Olsson et al. } \\
\text { (2013) }\end{array}$ & $\begin{array}{l}\text { Qualitative \& } \\
\text { experimental }\end{array}$ & AR & Physical store & $\begin{array}{l}\text { Various (apparel, } \\
\text { services) }\end{array}$ \\
\hline $\begin{array}{l}\text { Cuomo et al. } \\
\text { (2014) }\end{array}$ & $\begin{array}{l}\text { Literature } \\
\text { review }\end{array}$ & AR & $\begin{array}{l}\text { Online \& physical } \\
\text { store }\end{array}$ & $\begin{array}{l}\text { Various } \\
\text { (furniture, food, } \\
\text { games, apparel) }\end{array}$ \\
\hline $\begin{array}{l}\text { Huang \& Hsu Liu } \\
\text { (2014) }\end{array}$ & Quantitative & AR & $\begin{array}{l}\text { Online store; } \\
\text { Online AR fitting } \\
\text { tested in laboratory }\end{array}$ & $\begin{array}{l}\text { Various (apparel, } \\
\text { furniture) }\end{array}$ \\
\hline $\begin{array}{l}\text { Martínez et al. } \\
\text { (2014) }\end{array}$ & $\begin{array}{l}\text { Literature } \\
\text { review }\end{array}$ & AR & $\begin{array}{l}\text { Online \& physical } \\
\text { store }\end{array}$ & $\begin{array}{l}\text { Various (apparel, } \\
\text { make up, } \\
\text { furniture, food, } \\
\text { automotive) }\end{array}$ \\
\hline $\begin{array}{l}\text { Poncin \& } \\
\text { Mimoun (2014) }\end{array}$ & Quantitative & AR & Physical store & Toys \\
\hline $\begin{array}{l}\text { Ström et al. } \\
(2014)\end{array}$ & $\begin{array}{l}\text { Literature } \\
\text { review }\end{array}$ & $\begin{array}{l}\text { Mobile device } \\
\text { applications } \\
\text { including AR }\end{array}$ & $\begin{array}{l}\text { Online store } \\
\text { (mobile) }\end{array}$ & $\begin{array}{l}\text { Various (game, } \\
\text { financial } \\
\text { services) }\end{array}$ \\
\hline $\begin{array}{l}\text { Huang \& Liao } \\
\text { (2015) }\end{array}$ & Quantitative & AR & $\begin{array}{l}\text { Online store; } \\
\text { Online AR fitting } \\
\text { tested in laboratory }\end{array}$ & Apparel \\
\hline Javornik (2016) & $\begin{array}{l}\text { Literature } \\
\text { review }\end{array}$ & AR & $\begin{array}{l}\text { Online \& physical } \\
\text { store }\end{array}$ & $\begin{array}{l}\text { Various } \\
\text { (furniture, } \\
\text { apparel, make up, } \\
\text { food) }\end{array}$ \\
\hline
\end{tabular}




\begin{tabular}{|c|c|c|c|c|}
\hline $\begin{array}{l}\text { Altarteer et al. } \\
(2017)\end{array}$ & Quantitative & VR & $\begin{array}{l}\text { Online store; } \\
\text { Tested in } \\
\text { laboratory }\end{array}$ & Accessories \\
\hline $\begin{array}{l}\text { Bonetti et al. } \\
\text { (2017) }\end{array}$ & $\begin{array}{l}\text { Literature } \\
\text { review }\end{array}$ & AR \& VR & $\begin{array}{l}\text { Online \& physical } \\
\text { store }\end{array}$ & $\begin{array}{l}\text { Various (apparel, } \\
\text { make up, } \\
\text { furniture) }\end{array}$ \\
\hline Dacko (2017) & Quantitative & $\mathrm{AR}$ & Physical store & $\begin{array}{l}\text { Various (apparel, } \\
\text { wall painting, } \\
\text { games) }\end{array}$ \\
\hline $\begin{array}{l}\text { Hwangbo et al. } \\
\text { (2017) }\end{array}$ & Quantitative & $\begin{array}{l}\text { Immersive } \\
\text { technologies } \\
\text { including AR }\end{array}$ & Offline store & Apparel \\
\hline $\begin{array}{l}\text { Pantano et al. } \\
(2017)\end{array}$ & Quantitative & AR & Online store & Eyewear \\
\hline $\begin{array}{l}\text { Papagiannidis et } \\
\text { al. (2017) }\end{array}$ & Quantitative & VR & $\begin{array}{l}\text { Online store; } \\
\text { Tested in } \\
\text { laboratory }\end{array}$ & Apparel \\
\hline $\begin{array}{l}\text { Poushneh \& } \\
\text { Vasquez-Parraga } \\
\text { (2017) }\end{array}$ & Quantitative & AR & $\begin{array}{l}\text { Online store; } \\
\text { Tested in } \\
\text { laboratory }\end{array}$ & Eyewear \\
\hline $\begin{array}{l}\text { Willems et al. } \\
\text { (2017) }\end{array}$ & $\begin{array}{l}\text { Literature } \\
\text { review }\end{array}$ & $\begin{array}{l}\text { Shopper- } \\
\text { oriented } \\
\text { technologies } \\
\text { including AR }\end{array}$ & Offline store & $\begin{array}{l}\text { Various (e.g. } \\
\text { apparel, food, } \\
\text { make up, etc.) }\end{array}$ \\
\hline
\end{tabular}

Table 1 Typology of key studies on human-computer interaction with immersive technologies in retail settings

As evidenced within Table 1, research on AR in retail largely concerns online stores and is conducted in controlled laboratory environments (Huang and Liao, 2015; Pantano and Laria, 2012; Papagiannidis et al., 2017). There is a relative paucity of research conducted in physical store settings. However, as physical stores have adopted these technologies, there is an increasing need and opportunity to conduct research in this real-world context. In their review of research methods applied in HCI with mobile devices, Kjeldskov and Graham (2003) noted the tendency towards building systems and evaluating consumers' usage and interaction within artificially controlled environments and isolated laboratory-based settings. This comes at the expense of understanding and learning from the actual use of technologies in 'messy' 
real-world contexts (Dix, 2009), characterised by distractions, noise and interruptions (Rogers, 2004).

\section{Empirical research context}

A sportswear fashion retailer located in central London (UK) was selected as a context to collect empirical evidence of consumers' perception of their immersion in the augmented store. This retailer sells sportswear and outerwear and an overall lifestyle concept. It occupies a premium market positioning, with an innovative and active brand image, due to the innovative materials used in products, the sports activities organised by the retailer, and in-store technologies. The retailer focuses heavily on in-store experience and creating a community among customers, in part by devoting a section of the premises to a café area, thereby providing a place where customers can meet, relax, work, and watch sports events.

The store space was scanned and virtually reconstructed to realise a $3 \mathrm{D}$ model of the store, which consumers could further experience virtually, when physically present in the real store. This allowed the development of an immersive environment which was installed in the store for the purpose of this study. Three key products and a real model were scanned in detail, to visualise how a product would look when worn, as well as to increase the sense of realism of the experience. Tags, or points of engagement, were further inserted on specific items such as new products at the store entrance to welcome customers, and on the in-store images of sports activities organised by the brand. From the highlighted items, tags would pop up by clicking on or walking by them, giving suggestions to the user and providing further information on a product or sports event, linking and redirecting the user to the brand's website and e-store, allowing customers to purchase items and view videos of sports events 
showcased. This served to immerse the user in the enhanced environment and space, enabling interaction through the conduit of the technology (Figure 1). This 3D model can be used with all types of screens and VR headsets to help confer an immersive and enhanced customer experience whilst in the physical store.

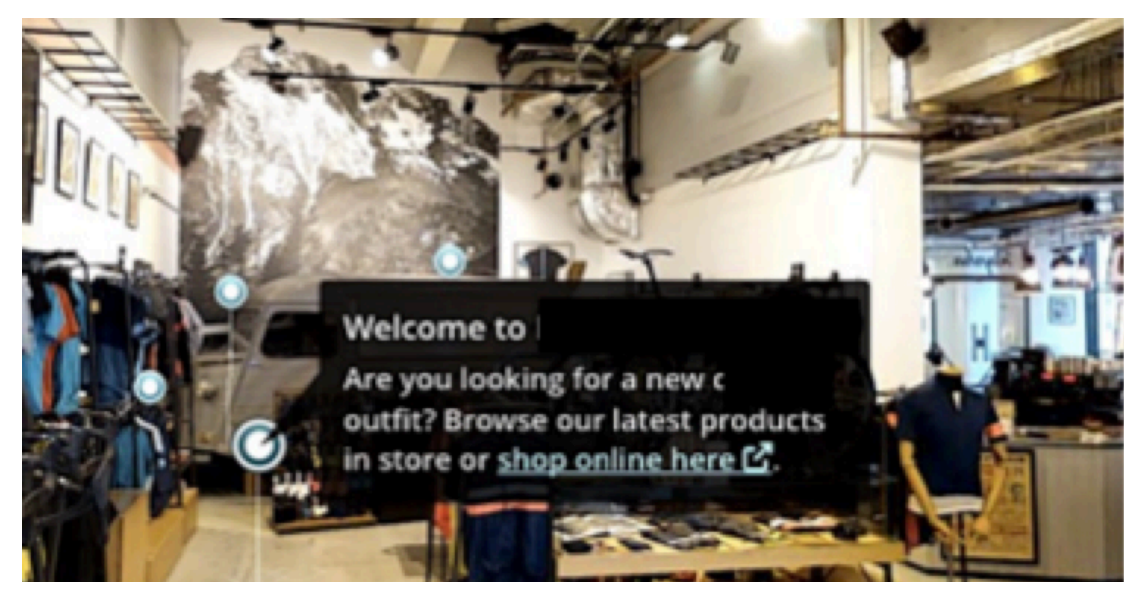

Fig. 1. Example of a point of engagement, as visualised by consumers, welcoming customers, giving information and redirecting users to the retailer's e-store (Courtesy

$$
\text { of retailer) }
$$

\section{Methodology}

Qualitative research inquiry was used to evaluate users' reaction to immersion in an augmented store integrated with AR, to gain an in-depth understanding of the effect on behaviour. The majority of studies on technology adoption and usage in retail settings adopt a broadly positivistic perspective (e.g. Ha and Stoel, 2009; Huang and Liao, 2015; Pantano et al., 2017; Roy et al., 2018), often applying the Technology Acceptance Model (Davis, 1989), extending and combining it with other frameworks and constructs (see for example, Gangwar et al., 2015; Papagiannidis et al., 2017; Roy et al., 2018; Venkatesh et al., 2012). However, researchers increasingly stress the 
need for more interpretive methods in this context in order to gain a richer, more comprehensive understanding (Korpelainen, 2011; Rowlands, 2005; Williams et al., 2009). Technology adoption is a complex phenomenon (Rowlands, 2005), involving understanding of the unique points of view of the participants involved, human experiences and participant characteristics, the context in which adoption takes place, and the intricate and rapidly changing nature of technology (Pantano and Priporas, 2016). Consequently, there have been calls for qualitative and interpretive approaches to the phenomenon of technology adoption (Korpelainen, 2011; Rowlands, 2005; Williams et al., 2009). Hence, this qualitative study aims to deliver rich and in-depth qualitative evidence to inform deeper understandings of consumer perceptions of AR in a 'real-world' physical retail setting.

\subsection{Procedure and data collection}

A convenience sample of 29 participants available at the time and place where the investigation was conducted was randomly recruited by being approached in-store to take part in the research, which consisted of structured observation of participants trying out the technology, and their reactions to it. Field notes and pictures were used to record the results of the observations. This was followed by interviews (lasting approximately 30 minutes). The selection criteria were: 1) that participants were current loyal customers; and 2) were willing to take part in the research. The sample consisted of 27 male and two female participants, as the brand's target market is predominantly male-oriented consisting of 30-50-year-old males; successful, affluent, pursuing a certain active lifestyle, and loyal to the sport category. Three participants were aged between 20-24; seven between 25-29, two between 30-34, one between 3539, twelve between 40-49, and four between 50-60. In terms of frequency of 
shopping at the brand premises, seven participants visited the store once a week, eleven once a month, and twelve once every six months. Sample composition was consistent with the intention of the research, which was not to generalise to a wider population, as this was a qualitative study driven by the intention to gather rich, indepth insights to inform deeper understanding of the phenomenon of interest.

Participants were first asked to try out the new technology on three formats - laptop, iPad screens, and a VR headset - whilst in the physical store, and use each format to experience and autonomously explore the environment and the immersive and augmented store experience, navigating the augmented space, exploring and interacting with it, on both screens and headset, moving around, walking across the virtual store, viewing products in detail and looking at product information, suggestions, links to the brand's e-store and videos of sports events. The technology included 3D, VR, headset, mobile phones compatible with the headset, computers and tablets.

Subsequently, participants were asked about their experience. Interview questions and themes for discussion were formulated to investigate perceptions of the degree of enhancement of the customer experience and the physical environment (i.e. shopping experience; level of immersion and engagement; degree of realistic experience; visibility and presentation of products and space), interaction with the technologies used (i.e. degree of realistic interactions; degree of immersion in the store space and environment; time spent in-store; brand engagement; perception of the brand; purchase decisions), and further suggestions and considerations (See Appendix 1).

Each participant was invited to talk openly and express their perceptions and feelings in their own words. The questions were worded clearly and neutrally, to avoid bias 
and enable respondents to answer freely and contribute as much detailed information as they wished (Irvine et al., 2013). Notes were taken and typed into an online semistructured interview template to facilitate data collection.

Beginning with interview transcription and familiarisation, data analysis followed an established inductive process (Corbin and Strauss, 2008; Miles et al., 2014) of applied thematic analysis (Guest et al., 2002). Following this widely accepted process, a detailed and in-depth examination of participants' feelings, opinions and behaviours, were examined to initially identify open, and then as the process evolved, axial codes (Corbin and Strauss, 2008). The coding of data proceeded iteratively (Spiggle, 1994) and meaning was conceptualised by selectively reducing and condensing the final selection of core themes. These selective codes were reviewed, refined and grouped into a final set of core themes, representing some more general phenomena. Codes were revised throughout the analysis as a consequence of immersion in the data (Morse, 1994). Finally, three core themes were identified: store perception; interaction; and behaviour, which form the structural and discursive basis of the following analysis of findings.

\section{Research findings}

\subsection{Store perception: the new shopping experience}

In terms of participants' perception of the new store environment enriched with AR technology, most participants $(n=26)$ commented that this immediately enhanced their shopping experience. Participants appreciated the novel in-store experience, and considered the enriched store to be entertaining, engaging, immersive and enjoyable. One commented: 
"It's engaging and it puts you right in the centre of the experience"

Some participants indicated that the immersive technologies served to make the instore experience highly customised, which helped the retailer create a closer relationship with the customer, and further enhanced perceived service quality and customer experience (Roy et al., 2017):

"It facilitates a more tailored customer experience that is both engaging and interesting. "

This aligns with Poncin et al.'s (2017) view that customers' interaction with the technology and the smart store contribute to enhance the retail experience. From observational and interview data, participants were generally favourable towards the 3D models and the augmented store, and the resulting enhanced in-store experience, and also revealed a positive disposition to future developments relating to this form of store and innovative technologies.

However, three participants did not find this new store type to contribute positively to their shopping experience. This could be linked to their degree of acceptance, attitudes and behavioural intentions towards innovative technologies, which could depend on several factors, including perceived usefulness, perceived ease-of-use, consumers' characteristics (i.e. level of cognitive innovativeness, level of education, age, store channel preferences, consumer well-being), attitudes about the technology (i.e. degree of familiarity and understanding of how to use a specific tool, confidence in using it in public, word-of-mouth intentions, behavioural intentions, system characteristics) and context constraints (i.e. time availability, customer experience, sources of information, perceived risk, store crowding, technology location in-store, store reputation) (Bell et al., 2017; Davis, 1989; Huang and Liao, 2015; McCormick 
et al., 2014; Poncin et al., 2017; Roy et al., 2017; Roy et al., 2018). Some participants stressed that, as these technologies were still quite new, they needed to get used to them, especially in a retail context:

"I have not used it [immersive technology] for browsing products before. Up until now the experience of it has been novelty games on the iPhone."

Thus, consumers liked the concept underpinning the technology, but its unfamiliarity and the complexity of the functions (leading to more explorative possibilities) required were not perceived as intuitive. Consequently, participants felt they would need a trial period, or training, to be fully experienced to gain optimum benefit. Participants demonstrated a likelihood to explore the store using this technology for their purchases, however this would need to be supported and supplemented by store employees. This suggests a need for retailers to introduce this new technology gradually, making it as intuitive as possible, educating the end users, and promoting the new tool by providing all relevant information (e.g. trained staff in-store, in-store posters and signs) (Lee et al., 2012; Piotrowicz and Cuthbertson, 2014). Moreover, the continuous advances in technologies (with emphasis on 3D graphics and input modalities), might reduce usage complexity and provide easier-to-use technologies that can limit the more negative implications of the above mentioned issues in physical stores, which did not occur in lab tests where researchers supervised the experiments and trained users accordingly (Papagiannidis et al., 2017).

\subsection{Interaction: Consumers' mobility and interaction with the emerging} augmented store

Most participants $(n=25)$ said they found the experience realistic, facilitated by the ability to walk around the enhanced store. Several were enthusiastic about the 
visibility and presentation of products and the store space, stressing the ability of the immersive technologies to enhance product visibility (in terms of features and fitting), which they found very realistic:

"It shows the space well, the colours are vibrant."

"It provides an immersive experience"

The enhanced store also helped users find what they were looking for, thus making the interaction informative (Antéblian et al., 2014; Huang and Liao, 2015; McCormick et al., 2014).

However, four participants expressed slightly negative perceptions, feeling the enhanced store did not provide an intuitive way to present and interact with products:

"I would prefer it [enhanced store], but it needs an easier way to look at products.”

Results revealed a prevalence of hedonic motivations for interacting with the enhanced store, with participants stressing the immersive, interactive and entertaining aspects of the enriched store:

"It makes the experience more engaging."

In particular, they acknowledged a desire to see this technology being used to tell the 'story' of the brand in more immersive ways, making the in-store experience more informative about the characteristics and values of the brand, and its associated sporting/brand community activities, instead of merely focusing on selling products. This is linked to the brand positioning and image as a lifestyle brand, and to the format of the store. These hedonic drivers underpinned participants' evaluations of the augmented store, leading to perceived enhancement of their experience. However, 
they also acknowledged the utilitarian benefits (i.e. product information, location, availability, being redirected to the retailers' e-store to place an order to speed up service etc.). This is consistent with previous studies showing both hedonic and utilitarian value of immersive AR/VR applications (Huang and Liao, 2015; Olsson et al., 2013; Willems et al., 2017).

Overall, participants liked the interactive elements of the enhanced store. Being able to move virtually from one part of the store to another, seeing the space through the immersive technology, and then be re-directed to the brand's website to get extra information or place an order, emerged as important aspects making participants' interactions with the 3D models favourably-perceived and realistic. This allowed users to interact with other retail channels whilst in the physical store. The adoption of innovative consumer-facing technologies has made the online and offline worlds more interrelated (Bell et al., 2017; Bonetti and Perry, 2017; McCormick et al., 2014), and perceived by the customer as integrated and as part of a unique, seamless experience (Piotrowicz and Cuthbertson, 2014; Verhoef et al., 2015; Willems et al., 2017).

\subsection{Behaviour: The influence of the augmented store}

Results showed the influence of the augmented store on consumer behaviour. This revealed short-term shopping and behavioural outcomes, and longer-term implications for brand perception and image, as reported below.

\subsubsection{Short-term outcomes: consumer behaviour}

Observational and interview data suggested positive participant reactions to the augmented store. Participants felt that the interaction with the innovative technologies 
and the enhanced store environment would encourage them to spend more time in the augmented store to interact with the immersive technologies:

"I would spend more time walking around, moving around."

Nine participants stated that the immersive technologies and the augmented store increased their desire to shop at the specific retailer:

"It [the augmented store] increases my desire to shop at [the brand]"

These short-term behavioural outcomes in relation to the influence of consumerfacing technology on consumer behaviour are in line with previous studies (Dacko, 2016; Poncin et al., 2017; Roy et al., 2018)

\subsubsection{Long-term implications: brand perception and image}

Some interviews suggested an effect of the new store on the brand perception and image. Indeed, many participants found the enhanced store entertaining, and commented that the interaction with the innovative technologies and the augmented store made them feel engaged with the brand $(n=21)$, and enhanced their perception of the brand image.

These reactions are in line with previous environmental psychology studies in a retail context which investigated the influence of consumer-facing technology on consumer satisfaction and loyalty to retailer that appears as an innovation-oriented retailer, which results in a more positive brand image (Roy et al., 2017). Accordingly, this research supports these previous studies by adding empirical evidence in a real-world scenario.

Generally, participants found the enhanced store to be different, entertaining, innovative, professional, modern and trendy. Such innovative in-store technical 
elements are in line with the retailer's identity, image and positioning, reinforcing how the retailer positions itself and is perceived by consumers and competitors (Pantano et al., 2017), as the retailer also uses innovative technologies and materials it its products. Two respondents commented:

"It pushes the boundaries, I am not surprised, it's the same idea as what they [the brand] are all about; they are innovative in the textile, high quality."

"It is trendy and keeps up with the digital experience, it keeps the brand updated."

\section{Discussion}

The augmented store can, thus, enhance the in-store shopping experience, enabling this new shopping environment to be perceived as immersive, entertaining, engaging and enjoyable. Participants perceived their interaction with the augmented store and the AR technology as immersive, engaging and realistic, and hedonic motivations for interacting with the technology prevailed, with benefits also for the retailer's brand image. Furthermore, the innovative technologies allowed participants to interact with multiple channels whilst in the physical store, thus contributing to channel integration. These aspects contributed to enhancing engagement with the brand and to enhance the perception of the brand value, thus increasing the participants' desire to shop at the retailer.

Table 2 below provides a summary of the core themes which emerged from the study, as well as notable aspects and insights for each theme. 


\begin{tabular}{ll}
\hline Core themes & Notable insights \\
\hline Store perception & Enhancement of the participants' shopping experience through the \\
& new store environment. \\
Interaction & New augmented store perceived as entertaining, engaging, \\
& enjoyable and immersive. \\
& Interaction with the augmented store perceived as a realistic \\
& experience. \\
& Enhanced and realistic visibility of product presentation and store \\
& space. \\
& Prevalence of hedonic motivations for technology interaction. \\
& Channel integration by interacting with multiple channels using \\
& immersive technologies within physical store. \\
& $\rightarrow$ Short-term outcomes: Interaction with the enhanced store \\
& environment and immersive technologies encourages participants \\
& to spend more time in store, and increases desire to shop at the \\
& retailer. \\
& $\rightarrow$ Longer-term implications: Interaction with the innovative \\
& technologies leads to brand engagement and enhancement of \\
& brand perception and image.
\end{tabular}

Table 2 Impact of augmented store characteristics on consumer behaviour and perceptions

Building on these findings, the following discussion suggests ways to further develop new store formats, enhanced through AR, at a moment in time where the adoption of new immersive technologies are increasingly being considered by retailers as a means to enrich the traditional point of sale, in the search for differentiation and/or competitive advantage. Resonating with the notion of 'augmented places' discussed above, a schematic framework for the proposed 'augmented store' is outlined below. 
We also discuss the relevance of the research findings with consumer-owned smart AR.

\subsection{Store Augmentation: The development of a new store format}

The augmented store can be defined as a physical store enriched with AR to create innovative immersive virtual experiences in the real world. In this store format, the customer's current perception of the physical space, environment and shopping experience are mediated and enhanced by the use of 3D models and virtual scenarios that consumers explore and naturally interact with while in the physical store environment. These innovative technologies are central to the concept of the augmented store, as shown in Figure 2, which extends the traditional physical retail space boundaries surrounding the customer (such as the physical limits of the store, the items physically available in the store, the information at consumers' disposal and the way it is provided) towards a simultaneous real-world and digital experience. Therefore, consumers' natural interactions with the store environment - through innovative and realistic interfaces, space mobility and visibility - constitute another key feature of this form of store. This offers new possibilities for consumers to observe and interact with virtual objects, not physically available in the real store space, by enriching content and enabling a deeper participation with the experience. The outcome confers a richer and more immersive perception of the augmented store environment, shopping experience, entertainment quotient, and overall enjoyment of the physical store; all factors providing notable benefits for retailer's brand image. 


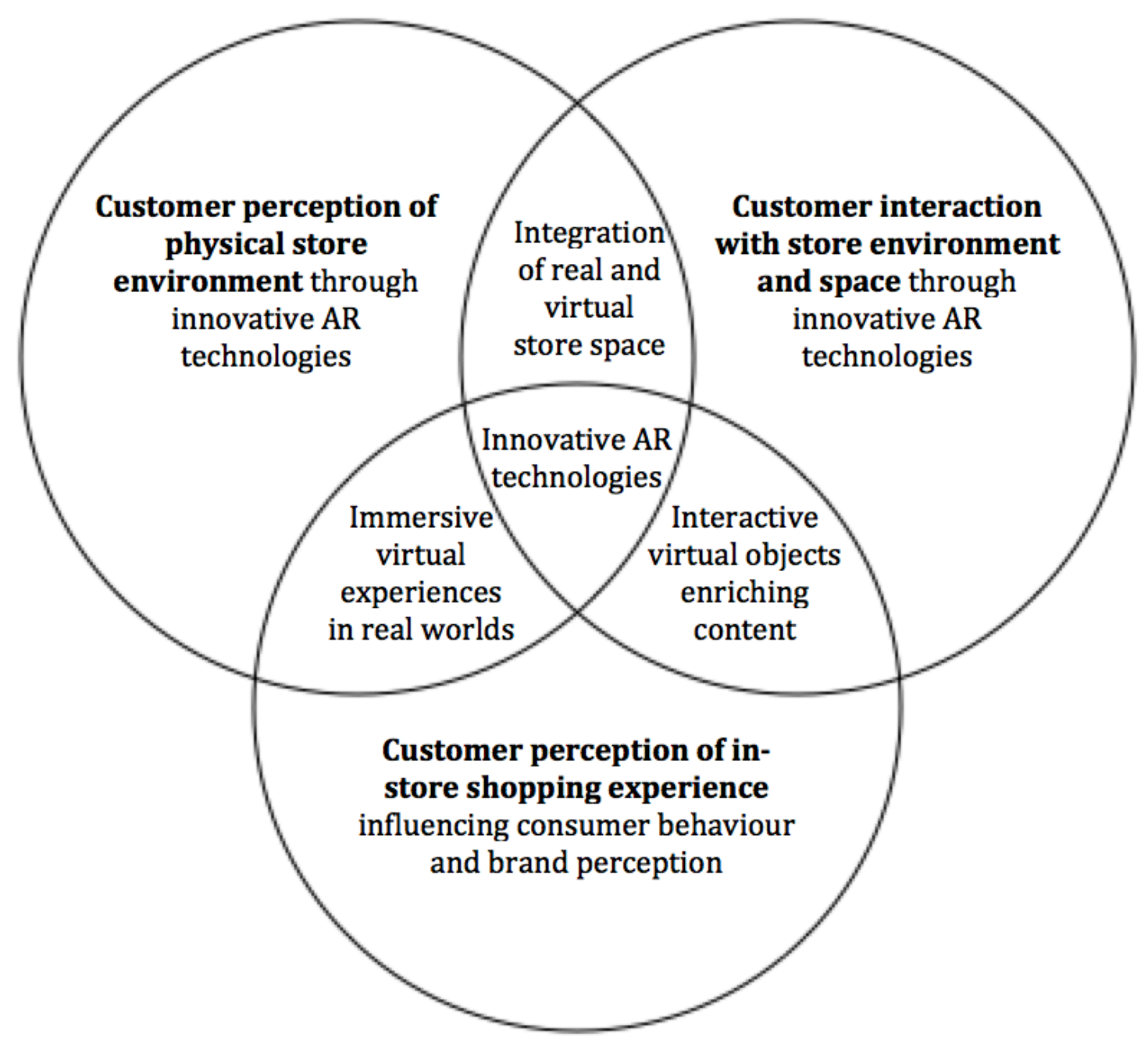

Fig. 2. Key characteristics of the augmented store

\subsection{Consumer-owned AR in the augmented store}

Researchers have stressed the need for retail stores to become 'smarter' and provide greater consumer value (Pantano and Priporas, 2016), at a time where consumers increasingly adopt and use innovative technologies, many of which are smart personal technologies such as mobile AR apps on personal mobile devices and AR Smart Glasses (Dacko, 2016; Javornik, 2016). 
Applying the findings from this research to incorporate consumers' personal AR technologies, these forms of technology have the potential to further enhance the store environment and shopping experience. Consumer interaction with personal AR enabling devices whilst in the enhanced store could further contribute to mobility and visibility of spaces and products, thus making the experience better perceived and realistic. This could then lead to an enhancement of brand perception and an increased feeling of immersion in the store environment and space, and increased engagement with the brand. Dacko (2016) showed how these forms of smart technologies help enhance user satisfaction and experiential benefits, as well as perception of brand value. This can be linked to consumers' increased perceived control and autonomy with using personal AR technologies as a form of consumerled interaction and personalisation whilst in retail settings (Poncin et al., 2017; Roy et al., 2017).

Although predictions of the possibilities for such technology use will inevitably be contingent on future developments, we can speculate that the future store will be strongly based on technology that would replace some traditional in-store operations. Similarly, concerning in-store technologies, AR could become more personal and customised with new personalised interaction modalities. This interaction will further result into unique shopping experiences that vary between consumers. On the other hand, the possible technology-based store could raise potential ethical issues concerning consumers' sensitive data storage and management, and also children's interaction in the new stores, which will require further investigation. 


\section{Conclusions, contributions and future research}

This study explores the integration of AR within a physical store and suggests ways to develop a new store format - the augmented store - by integrating AR to make the store enriched, enhanced, more accessible, entertaining and efficient for consumers in terms of product information, promotions, location, product try-on and stock availability. Results show that participants generally perceive the new augmented store to be more immersive, entertaining, engaging and enjoyable. They find the interaction with the store realistic, leading to an enhanced brand perception and increasing brand engagement.

\subsection{Theoretical contributions and managerial implications}

This study contributes to the existing literature in three main ways. First, it extends the existing literature on augmented and immersive places (Carmigniani et al., 2011; Chang et al., 2015; Oleksy and Wnuk, 2016) to the specific real-world context of the physical store, by providing knowledge on the shift towards an augmented store and outlining its key characteristics. To this end, an illustrative framework has been provided (Figure 2), outlining the key characteristics of the augmented store. These include consumers' perception of the physical store environment enhanced by innovative AR technologies, consumers' natural interactions with the store environment through innovative AR technologies, and how these aspects contribute to confer a richer and more immersive consumer perception of the augmented store environment.

Second, it contributes to the existing literature on HCI (Kjeldskov and Graham, 2003; Rogers, 2004) by focusing on consumers' interaction with the technology (consumercomputer interaction or CCI), thus extending existing research on a generic user's 
interaction with technology in a generic place. In particular, the study focuses on consumers' interactions with AR technologies in a real-world context of an actual store. Third, this study extends previous research conducted in simulated and controlled laboratory environments with simulated consumers (Pantano and Laria, 2012; Pantano et al., 2017; Papagiannidis et al., 2017), by investigating perceptions of current actual consumers of a retailer, their interactions with immersive AR technologies in a real, physical retail store, and their reactions to the new and enhanced store space and environment.

In terms of industry implications, this study unveils positive consumer reactions to the augmented store format, providing practitioners with a fresh perspective on a specific new technology to be successfully integrated within more traditional pointof-sale formats. Retailers willing to further engage with customers by enhancing their in-store experience should therefore consider immersive technologies as a valuable means to provide entertaining, informative and engaging experiences.

\subsection{Future research}

Further research could focus on different retailers with varied target customers, to identify and analyse reactions from a more diverse population. Gaining a more comprehensive understanding could enable retailers to achieve a suitable balance of innovative technologies and traditional services provided in-store, to better satisfy a broader range of target customers. Using eye-tracking technology, or analysing retailers' EPOS data, could also provide insights linking consumer perceptions to purchase behaviour; for example, by exploring whether consumers would spend more time in-store due to an enhanced experience, or whether it influences purchase intention. Overall, as consumers' degree of acceptance and adoption of innovative 
AR applications plays an important role in retailers' decisions to adopt the technology, further research is needed on the managerial implications deriving from this. Further investigation of how consumer-owned AR enabling devices, combined with the physical store enhanced with AR, could impact on users' interaction with, and perception of, the enhanced store, could also be conducted. Finally, future research could investigate managerial perspectives of consumers' reactions to, and perceptions of, the augmented store.

\section{References}

Ailawadi, K. L., \& Farris, P. W. (2017). Managing multi-and omni-channel distribution: metrics and research directions. Journal of Retailing, 93(1): 120-135.

Altarteer, S., Charissis, V., Harrison, D. \& Chan, W. (2017). Development and Heuristic Evaluation of Semi-immersive Hand-Gestural Virtual Reality Interface for Luxury Brands Online Stores. In L. De Paolis, P. Bourdot, \& A. Mongelli (Eds.) Augmented Reality, Virtual Reality, and Computer Graphics. AVR 2017 (pp. 464477). Springer, Cham.

Antéblian, B., Filser, M. \& Roederer, C. (2014). Consumption experience in retail environments: A literature review, Recherche et Applications en Marketing, 28(3):82-109.

Augé, M. (1992). Non-places: Introduction to an Anthropology of Supermodernity. London: Verso.

Bailey A.A., Pentina I., Mishra A.S. \& Ben Mimoun M.S. (2017). Mobile payments adoption by US consumers: an extended TAM. International Journal of Retail and Distribution Management, 45 (6):626-640. 
Bell, D.R., Gallino, S. \& Moreno, A. (2017). Offline showrooms in omnichannel retail: demand and operational benefits. Management Science, 64 (4):1629-1651.

Bertacchini, F., Bilotta, E., \& Pantano, P. (2017). Shopping with a robotic companion. Computers in Human Behavior, 77:382-395.

Bonetti, F. \& Perry, P. (2017). A Review of Consumer-Facing Digital Technologies Across Different Types of Fashion Store Formats, In Vecchi, A. (Ed.), Advanced Fashion Technology and Operations Management. Pp. 137-163, IGI Global, Hershey PA, USA.

Bonetti, F., Warnaby, G. \& Quinn, L. (2017). Augmented Reality and Virtual Reality in Physical and Online Retailing: A Review, Synthesis and Research Agenda, In Jung, T. and Tom Dieck, M. (Eds.), Augmented Reality and Virtual Reality. Pp. 119132, Springer, Cham, Switzerland.

Bonetti, F., Perry, P., Warnaby, G. \& Quinn, L. (2018). Evaluating Managerial Drivers and Barriers to the Implementation of In-Store Technology in Fashion Retailing. Extended abstract presented at the Academy of Marketing Science World Marketing Congress (AMS), Porto, Portugal, June 27-30 2018.

Bozer, Y.A. \& Aldarondo, F.J. (2018). A simulation-based comparison of two goodsto-person order picking systems in an online retail setting. International Journal of Production Research, in press.

Carmigniani, J., Furht,B., Anisetti,M., Ceravolo,P., Damiani,E. \& Ivkovic, M. (2011). Augmented reality technologies, systems and applications, Multimedia Tools and Applications. 51:341-377.

Chang, K.-E., Chang, C.-T., Hou, H.-T., Sung, Y.-T., Chao, H.-L., \& Lee, C.-M. (2014). Development and behavioral pattern analysis of a mobile guide system with 
augmented reality for painting appreciation instruction in an art museum. Computers \& Education, 71:185-197.

Chang Y.-L, Hou H.-T, Pan C.-Y, Sung Y.-T. \& Chang K.-E. (2015). Apply an augmented reality in a mobile guidance to increase sense of place for heritage places, Educational Technology and Society, 18(2):166-178.

Chesbrough, H. (2010). Business Model Innovation: Opportunities and Barriers, Long Range Planning, 43(2/3):354-63.

Childers, T. L., Carr, C. L., Peck, J. \& Carson, S. (2001). Hedonic and utilitarian motivations for online retail shopping behaviour. Journal of Retailing, 77:511-535.

Corbin, J. \& Strauss, A. (2008). Basics of Qualitative Research: Techniques and Procedures for Developing Grounded Theory. Sage: Thousand Oaks, CA.

Cuomo, M.T., Tortora, D. \& Metallo, G. (2014). In store augmented reality: retailing strategies for smart communities. Mondo Digitale, 49:1-12.

Dacko, S. G. (2016). Enabling smart retail settings via mobile augmented reality shopping apps, Technological Forecasting and Social Change, 124:243-256

Davis, F.D. (1989). Perceived usefulness, perceived ease of use, and user acceptance of information technology, MIS Quarterly, 13(3):319-340.

Dennis C., Josko Brakus J., Gupta S., \& Alamanos E. (2014). The effect of digital signage on shoppers' behavior: the role of the evoked experience. Journal of Business Research, 67:2250-2257.

Dix, A. (2009). Human-Computer Interaction, In Liu, L. and Tamer Ozsu, M. (Eds.) Encyclopedia of Database Systems. Pp. 1327-1331, Springer US.

Dunleavy, M. \& Dede, C. (2013). Augmented Reality Teaching and Learning. In Spector J., Merrill M., Elen J., Bishop M. (Eds.), Handbook of Research on Educational Communications and Technology (pp. 735-745). Springer, New York. 
Foster, J. \& McLelland, M. A. (2014). Retail atmospherics: The impact of a brand dictated theme, Journal of Retailing and Consumer Services, 22:195-205.

Fuchs, C. \& Schreier, M. (2011). Customer empowerment in new product development. Journal of Product Innovation Management, 28(1):17-32.

Gangwar, H., Date, H. \& Ramaswamy, R. (2015). Understanding determinants of cloud computing adoption using an integrated TAM-TOE model. Journal of Enterprise Information Management. 28(1):107-130.

Guest, G., MacQueen, K. \& Namey, E. (2012). Applied Thematic Analysis. Sage: Thousand Oaks, CA.

Ha, S. \& Stoel, L. (2009). Consumer e-shopping acceptance: Antecedents in a technology acceptance model, Journal of Business Research, 62(5):565-571.

Huang, T.-L. \& Hsu Liu, F. (2014). Formation of augmented-reality interactive technology's persuasive effects from the perspective of experiential value. Internet Research. 24(1):82-109

Huang, T.-L. \& Liao, S. (2015). A model of acceptance of augmented-reality interactive technology: the moderating role of cognitive innovativeness, Electronic Commerce Research. 15(2):269-295.

Hwangbo, H., Kim, Y.S. \& Cha K.J. (2017). Use of the smart store for persuasive marketing and immersive customer experiences: a case study of Korean apparel enterprise. Mobile Information Systems, 2017:1-17.

Inman J.J. \& Nikolova H. (2017). Shopper-facing retail technology: a retailer adoption decision framework incorporating shopper attitudes and privacy concerns. Journal of Retailing, 93(1):7-28. 
Irvine, A., Drew, P. \& Sainsbury, R. (2013). 'Am I not answering your questions properly?' clarification, adequacy and responsiveness in semi-structured telephone and face-to-face interviews. Qualitative Research. 13(1):87-106

Javornik, A. (2016). Augmented reality: Research agenda for studying the impact of its media characteristics on consumer behaviour, Journal of Retailing and Consumer Services. 30:252-261.

Jetter, J., Eimecke, J. \& Rese, A. (2018). Augmented reality tools for industrial applications: What are potential key performance indicators and who benefits? Computers in Human Behavior 87:18-33.

Kannan P.K. \& Li, H. (2017). Digital marketing: a framework, review and research agenda. International Journal of Research in Marketing, 34 (1):pp. 22-45.

Kjeldskov J. \& Graham C. (2003). A Review of Mobile HCI Research Methods, In Chittaro, L. L. (Ed.), Human-Computer Interaction with Mobile Devices and Service. Pp. 317-335, Springer, Berlin, Heidelberg

Kim, J. \& Forsythe, S. (2007). Hedonic usage of product virtualization technologies in online apparel shopping, International Journal of Retail \& Distribution Management, 35(6):502-514.

Korpelainen, E. (2011). Theories of ICT system implementation and adoption-A critical. Aalto University publication series, 1:14-17.

Kotler, P. (1973). Atmospherics as a Marketing Tool, Journal of Retailing, 49(4):4864.

Laria, G. \& Pantano, E. (2011). Immersive environments for an advanced technologybased store. Proceedings of 17th International Conference on Networked Computing and Advanced Information Management. IEEE, pp. 218-221. 
Lee, L., Meyer, T. \& Smith, J. S. (2012). Reinventing the Customer Experience: Technology and the Service Marketing Mix, In Kandampully, J. (Ed.) Service Management: The New Paradigm in Retailing, Springer New York, pp. 143-160.

Martínez, H., Skournetou, D., Hyppölä, J., Laukkanen, S. \& Heikkilä, A. (2014). Drivers and bottlenecks in the adoption of augmented reality applications. Journal of Multimedia Theory and Application, 2(1):27-44.

McCormick, H., Cartwright, J., Perry, P., Barnes, L., Lynch, S. \& Ball, G. (2014). Fashion retailing - past, present and future, Textile Progress, 46(3):227-321.

McGrath, R. G. (2010). Business Models: A Discovery Driven Approach, Long Range Planning, 43(2/3):247-61.

Miles, M.B., Huberman, A.M., \& Saldana, J. (2014). Qualitative Data Analysis: A Methods Sourcebook, Sage: Thousand Oaks, California.

Morse, J. M. (1994). Critical Issues in Qualitative Research Methods. Sage: Thousand Oaks.

Oleksy, T. \& Wnuk, A. (2016). Augmented places: An impact of embodied historical experience on attitudes towards places, Computers in Human Behavior, 57:11-16.

Olsson, T., Lagerstam, E., Kärkkäinen, T. \& Väänänen, K. (2013). Expected user experience of mobile augmented reality services: a user study in the context of shopping centres, Personal and ubiquitous computing, 17(2):287-304.

Pantano, E. \& Laria, G. (2012). Innovation in retail process: from consumers' experience to immersive store design, Journal of Technology Management and Innovation, 7(3):198-206.

Pantano, E. \& Priporas, C.-V. (2016). The effect of mobile retailing on consumers' purchasing experiences: A dynamic perspective. Computers in Human Behavior, 61:548-555. 
Pantano, E., Rese, A. \& Baier, D. (2017). Enhancing the online decision-making process by using augmented reality: A two country comparison of youth markets, Journal of Retailing and Consumer Services, 38:81-95.

Pantano, E. \& Servidio, R. (2012). Modeling innovative points of sales through virtual and immersive technologies. Journal of Retailing and Consumer Services, 19(2), 279-286.

Papagiannidis, S., Pantano, E., See-To, E., Dennis, C. \& Bourlakis, M. (2017). To immerse or not? Experimenting with two virtual retail environments, Information Technology and People, 30(1):163-188.

Pham T.T.T. \& Ho J.C. (2015). The effects of product-related, personal-related factors and attractiveness of alternatives on consumer adoption of NFC-based mobile payments. Technology in Society, 43:159-172.

Piotrowicz, W. \& Cuthbertson. R. (2014). Introduction to the special issue information technology in retail: toward omnichannel retailing. International Journal of Electronic Commerce. 18(4):5-16.

Poncin, I., \& Mimoun, M. S. B. (2014). The impact of "e-atmospherics" on physical stores. Journal of Retailing and Consumer Services. 21(5):851-859.

Poncin I., Garnier M., Mimoun M.S.B. \& Leclercq T. (2017). Smart technologies and shopping experience: are gamification interfaces effective? The case of the Smartstore. Technological Forecasting and Social Change, 124:320-331.

Poushneh, A. \& Vasquez-Parraga, A. Z. (2017). Discernible impact of augmented reality on retail customer's experience, satisfaction and willingness to buy. Journal of Retailing and Consumer Services, 34:229-234. 
Puccinelli, N. M., Goodstein, R. C., Grewal, D., Price, R., Raghubir, P. \& Stewart, D. (2009). Customer Experience Management in Retailing: Understanding the Buying Process. Journal of Retailing, 85(1):15-30.

Ram, S. \& Sheth, J. N. (1989). Consumer Resistance to Innovations: The Marketing Problem and its solutions. Journal of Consumer Marketing, 6(2):5-14.

Rauschnabel, P. A. (2018). Virtually enhancing the real world with holograms: An exploration of expected gratifications of using augmented reality smart glasses. Psychology \& Marketing, 35(8):557-572.

Rauschnabel, P. A., He, J., \& Ro, Y. K. (2018). Antecedents to the adoption of augmented reality smart glasses: A closer look at privacy risks. Journal of Business Research, 92, 374-384.

Rogers, Y. (2004). New Theoretical approaches for Human-Computer Interaction, Annual Review of Information, Science and Technology, 38:87-143.

Roggeveen, A. L., Nordfält, J. \& Grewal, D. (2015). Do digital displays enhance sales? Role of retail format and message content, Journal of Retailing, 92(1):122-131. Rowlands, B. H. (2005). Grounded in practice: Using interpretive research to build theory, The Electronic Journal of Business Research Methodology, 3(1):81-92.

Roy, S. K., Balaji, M. S., Sadeque, S., Nguyen, B., \& Melewar, T. C. (2017). Constituents and consequences of smart customer experience in retailing. Technological Forecasting and Social Change, 124:257-270.

Roy S.K., Halaji M.S., Quazi A. \& Quaddus M. (2018). Predictors of customer acceptance of and resistance to smart technologies in the retail sector. Journal of Retailing and Consumer Services, 41:147-160. 
Schierz P.G., Schilke O. \& Wirtz B.W. (2010). Understanding consumer acceptance of mobile payment services: an empirical analysis. Electronic Commerce Research and Applications, 9 (3):209-216.

Sorescu, A., Frambach, R. T., Singh, J., Rangaswamy, A., \& Bridges, C. (2011). Innovations in retail business models. Journal of Retailing, 87:S3-S16.

Spiggle, S. (1994). Analysis and interpretation of in qualitative data in consumer research. Journal of Consumer Research, 21(3):491-503.

Ström, R. Vendel, M. \& Bredican. J. (2014). Mobile marketing: A literature review on its value for consumers and retailers. Journal of Retailing and Consumer Services, 21(6):1001-1012.

Sukaviriya, N., Podlaseck, M., Kjeldsen, R., Levas, A., Pingali, G. \& Pinhanez, C. (2003). Augmenting a retail environment using steerable interactive displays, Extended Abstracts on Human Factors in Computing Systems, ACM, CHI'03: 978979.

Tabușca, A. (2014). Augmented reality-need, opportunity or fashion', Journal of Information Systems \& Operations Management, 8(2):5-10.

Venkatesh, V., Thong, J. Y. L., \& Xu, X. (2012). Consumer acceptance and use of information technology: Extending the unified theory of acceptance and use of technology, MIS Quarterly, 36(1):157-178.

Verhoef, P. C., Kannan, P. K., \& Inman. J. J. (2015). From multi-channel retailing to omni-channel retailing: Introduction to the special issue on multi-channel retailing, Journal of Retailing, 91(2):174-181.

Willems K., Smolders A., Brengman M., Luyten K. \& Schoning J. (2017). The pathto-purchase is paved with digital opportunities: an inventory of shopper-oriented 
retail technologies. Technological Forecasting and Social Change, 124(2017):228242.

Williams, M. D., Dwivedi, Y. K., Lal, B. \& Schwarz, A. (2009). Contemporary trends and issues in IT adoption and diffusion research, Journal of Information Technology, 24(1):1-10.

\section{Appendix 1 Interview Guide}

\begin{tabular}{|c|c|}
\hline Topic area & Questions \\
\hline Introduction & $\begin{array}{l}\text { Tell me about your familiarity with the brand, } \\
\text { including purchases in both online and offline } \\
\text { store. }\end{array}$ \\
\hline \multirow[t]{3}{*}{ Shopping channel preferences } & Why do you prefer shopping online or offline? \\
\hline & $\begin{array}{l}\text { To what extent is this related to the provided } \\
\text { experience? }\end{array}$ \\
\hline & $\begin{array}{l}\text { To what extent are you influenced in this } \\
\text { choice by interactions with sales assistants? }\end{array}$ \\
\hline \multirow[t]{9}{*}{ Retail environment } & $\begin{array}{l}\text { In which way did the presence of } 3 \mathrm{D} \text { models } \\
\text { influence your shopping experience and why? }\end{array}$ \\
\hline & $\begin{array}{l}\text { Describe how you felt about the immersive } \\
\text { experience? }\end{array}$ \\
\hline & In which way did you consider it realistic? \\
\hline & Comparing the offline and online environment, \\
\hline & how important is the presence of immersive \\
\hline & and engaging technologies? \\
\hline & To what extent the 3D models improve your \\
\hline & experience while in the physical store, and in \\
\hline & the online one? \\
\hline Interaction & $\begin{array}{l}\text { To what extent do you consider the } \\
\text { interactions with the } 3 \mathrm{D} \text { models realistic? }\end{array}$ \\
\hline
\end{tabular}


To what extent do you consider the immersive experience in the virtual scenario realistic?

To what extent do these interactions influence your feeling of immersion in the store space and environment?

Wrap-up

Would you like to suggest any possible improvement of the technology?

Did you find any weaknesses in the experience due to the technology?

Do you have any other comments about the experience, environment and interactions modalities with the immersive technologies you would like to share? 